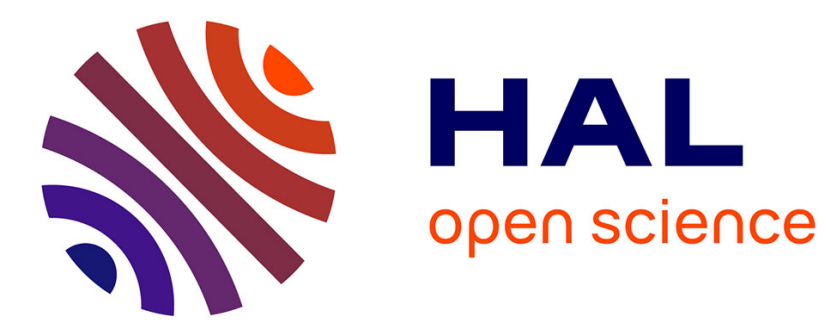

\title{
Inter-polyionic orientation in polyelectrolyte solution, observed by small angle neutron scattering
}

\author{
J.-P. Cotton, M. Moan
}

\section{To cite this version:}

J.-P. Cotton, M. Moan. Inter-polyionic orientation in polyelectrolyte solution, observed by small angle neutron scattering. Journal de Physique Lettres, 1976, 37 (4), pp.75-77. 10.1051/jphyslet:0197600370407500 . jpa-00231241

\section{HAL Id: jpa-00231241 https://hal.science/jpa-00231241}

Submitted on 1 Jan 1976

HAL is a multi-disciplinary open access archive for the deposit and dissemination of scientific research documents, whether they are published or not. The documents may come from teaching and research institutions in France or abroad, or from public or private research centers.
L'archive ouverte pluridisciplinaire HAL, est destinée au dépôt et à la diffusion de documents scientifiques de niveau recherche, publiés ou non, émanant des établissements d'enseignement et de recherche français ou étrangers, des laboratoires publics ou privés. 


\title{
INTER-POLYIONIC ORIENTATION IN POLYELECTROLYTE SOLUTION, OBSERVED BY SMALL ANGLE NEUTRON SCATTERING
}

\author{
J.-P. COTTON, \\ Laboratoire Léon-Brillouin (DPhG-SPSRM) \\ Centre d'Etudes Nucléaires de Saclay, 91190 Gif-sur-Yvette, France \\ M. MOA V \\ Laboratoire d'Hydrodynamique Moléculaire \\ Faculté des Sciences, 29283 Brest cédex, France \\ (Reçu le 13 octobre 1975, révisé le 5 janvier 1976, accepté le 28 janvier 1976)

\begin{abstract}
Résumé. - Un pic d'intensité de neutrons diffusés aux petits angles par une solution de polyélectrolyte est obtenu à une concentration supérieure à une concentration caractéristique $c_{0}$. Ce fait est interprété comme la preuve de l'existence d'un ordre entre les polyions étirés.
\end{abstract}

\footnotetext{
Abstract. - An intensity peak in small angle neutron scattering in a polyelectrolyte solution is found above a characteristic concentration $c_{0}$ of the polyelectrolyte. This is taken as evidence for ordering between the elongated polyions.
}

Polyelectrolytes are polymers having one or more ionizable groups per monomeric unit $(-\mathrm{COOH}$, for example). In solution, they are dissociated into polyvalent macroions (polyions) and a large number of small ions of opposite charge (counter-ions). The polyelectrolyte solution is characterized by the stochiometric degree of neutralization $\alpha_{s}$ of these ionizable groups with alkali (sodium hydroxide) and the polyelectrolyte concentration $c\left(\mathrm{~g} \cdot \mathrm{cm}^{-3}\right)$.

In pure aqueous solution, some properties of polyelectrolytes are well-known [1] : at a low, constant concentration $c$, the variation of $\alpha_{\mathrm{s}}$ from 0 to 1 increases the number of dissociated groups (or charges) and the polyion changes its configuration from a random coil $\left(\alpha_{s} \simeq 0\right)$ to an extended chain $\left(\alpha_{s} \geqslant 0.6-0.7\right)$; this elongation is caused by electrostatic interactions between the charged sites on the chain; at constant $\alpha_{s}$, the chain again contracts with increasing polyelectrolyte concentration.

Recent experiments on pure aqueous solutions, at concentrations low enough for the polyions to be in their stretched form, showed anomalous behaviour of the reduced viscosity. This suggested that electrostatic interactions caused ordered clustering of the polyions [2]; note that this ordering must disappear below a critical concentration $c_{0}$, so calculated that each stretched polyion can freely rotate about its centre of mass (see Table I).

A scattering technique is the most direct method of looking for this clustering.

\section{TABLE I}

$\begin{array}{lcccc}\alpha_{\mathrm{s}} & 0.27 & 0.6 & 0.9 & 1 \\ R_{\mathrm{g}}(\AA) & 33.7 & 74(* *) & 83(* *) & 88(* *) \\ C_{0}(*)\left(\mathrm{g} . \mathrm{cm}^{-3}\right) & 4.3 \times 10^{-2} & 2.5 \times 10^{-3} & 1.8 \times 10^{-3} & 1.5 \times 10^{-3} \\ L(\AA) & & 256 & 287 & 305 \\ \chi^{-1}(\AA) & & 35 & 34.5 & 34\end{array}$

$\left(^{*}\right) c_{0}$ has been calculated, for $\alpha_{\mathrm{s}} \geqslant 0.6$, assuming that the polyion is a rod of length $L: c_{0}=M /(\mathcal{N} . v), v=4 \pi(L / 2)^{3} / 3$, $M$ molecular weight and $\mathcal{N}$ Avogadro number; for $\alpha_{\mathrm{s}}=0.27$, the polyion is considered as a spherical coil of radius $(5 / 3)^{1 / 2} \times R_{\mathrm{g}}$.

(**) This approximate value has been obtained assuming that the peak has a negligible influence at small values of $q$ on the curve.

The need to resolve distances less than $300 \AA$ with sufficient solute-solvent contrast, suggests the use of small angle neutron scattering [3].

The measurements have been performed on a sample of Polymethacrylic acid [P.M.A. $\left(\mathrm{C}_{4} \mathrm{H}_{6} \mathrm{O}_{2}\right)_{n}$ ] of molecular weight $M_{\mathrm{v}} \simeq 13.000$, dissolved in heavy water. The chosen concentration $c=10^{-2} \mathrm{~g} . \mathrm{cm}^{-3}$ is higher than the concentration $c_{0}$ (see Table I) and low enough for the polyions to be in their straightened form. For these preliminary experiments, the parameter used was the degree of neutralization $\alpha_{s}$, set to values between 0.27 and 1 by the addition of sodium hydroxide to the aqueous polyelectrolyte solution; no simple electrolyte was added to the solution.

The scattered intensity was recorded by a multi- 
detector [4] of $(\rho, \theta)$ type, at a distance of $2.60 \mathrm{~m}$ from the sample, so that the momentum transfer

$$
q=(4 \pi / \lambda) \sin (\theta / 2)
$$

ranged from $10^{-2}$ to $10^{-1} \AA^{-1} ; \lambda$ is the wave-length (arithmetic mean $7.60 \AA$ ) and $\theta$ the scattering angle (3/260 to $31 / 260$ radian).

Generally, the intensity $I(\theta)$ scattered by polymers in dilute or not very concentrated solutions, decreases monotonically as $\theta$ increases. The curve in figure 1 shows this typical behaviour; this curve corresponds to a value of $\alpha_{\mathrm{s}}=0.27$, at which the polyion has the random coil configuration [5], and is similar to curves observed for non-ionic polymer solutions [6]. The

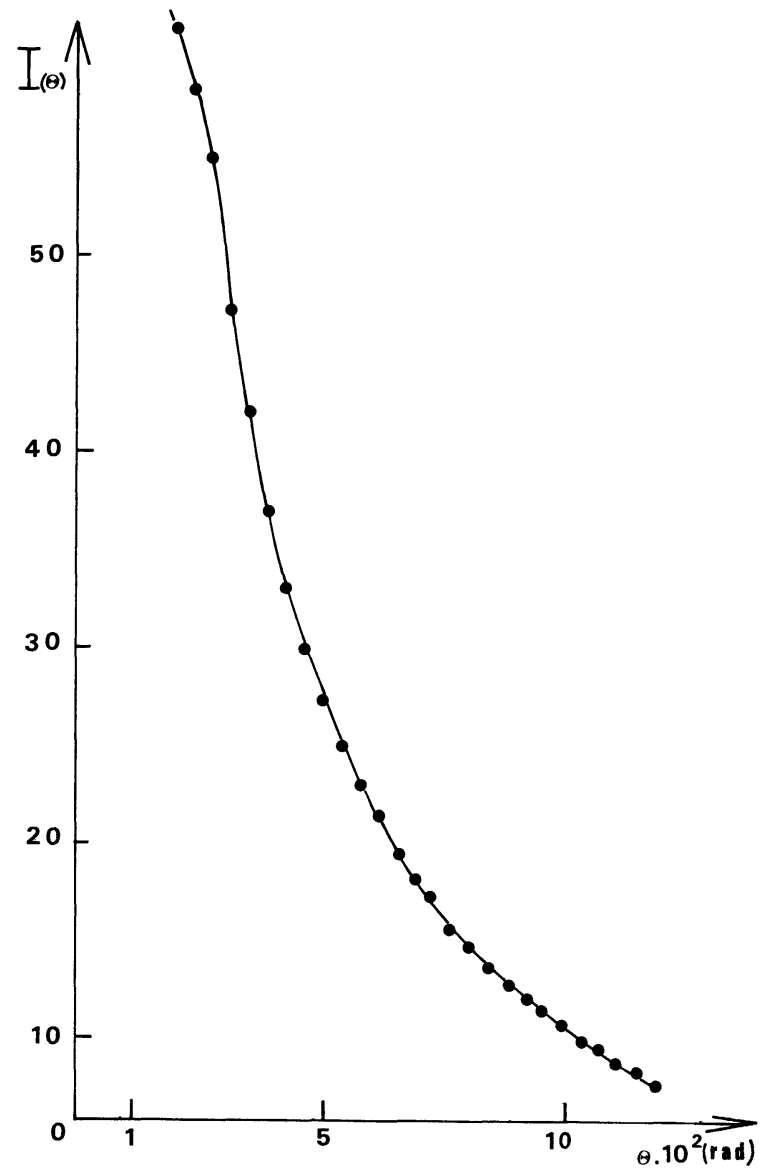

FIG. 1. - Variation of the scattered intensity $I(\theta)$ (in arbitrary unit) with the scattering angle $\theta$, for $\alpha_{\mathrm{s}}=0.27$.

apparent radius of gyration $R_{\mathrm{g}}$ of the particles can be estimated from the low $q$-value range of these curves (the Guinier range), using the following relation [7]

$$
I(\theta)=I(q) \sim I(0)\left(1-q^{2} R_{\mathrm{g}}^{2} / 3\right), q R_{\mathrm{g}}<1
$$

which gives the scattered intensity in the direction $\theta$. The $R_{\mathrm{g}}$ values so obtained [5] are given in the first line of the data table; for $\alpha_{s} \geqslant 0.6$, these values differ little from the radius of gyration of the fully stretched chain, showing the elongation of the polyion, which can be considered to be a rod or an ellipsoid of high axial ratio. This increase in polyion dimension further restricts the range of $q$ values for which the condition $q<1 / R_{\mathrm{g}}$ holds, and the $\boldsymbol{R}_{\mathrm{g}}$ values determined for $\alpha_{\mathrm{s}} \geqslant 0.6$ must be taken as minimum values.

For values of $\alpha_{\mathrm{s}}$ greater than 0.6 , the Guinier range is followed by a maximum, shown on figure 2 ; note that, at the same value of $\theta$, the scattered intensity is ten times lower for $\alpha_{s} \geqslant 0.6$ than for $\alpha_{s}=0.27$.

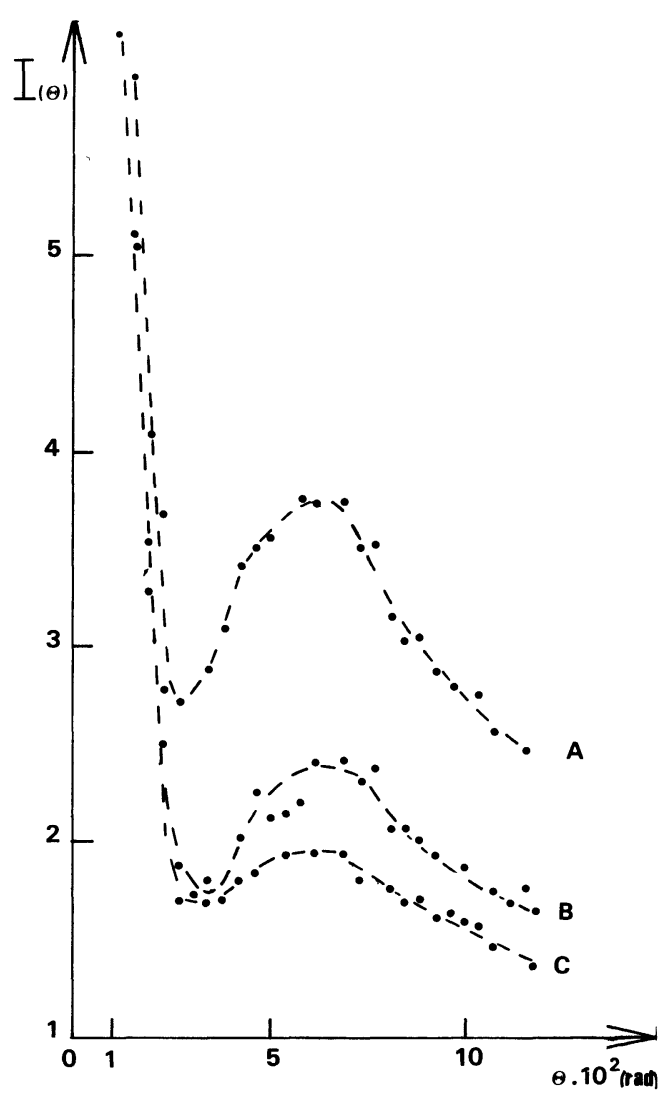

Fig. 2. - Variation of $I(\theta)$ with $\theta: \alpha_{\mathrm{s}}=0.6$, curve A, $\alpha_{\mathrm{s}}=0.9$, curve $B ; \alpha_{s}=1$, curve $\mathrm{C}$.

This maximum clearly shows that there is ordering of the particles; since it appears outside the Guinier range, it indicates that the average inter-particle distance $d$ is lower than the dimension of the particles and confirms the model of elongated chains ordered parallel to one another.

This is confirmed by the numerical values which can be deduced from the curves of figure 2. The distance $d$ obtained from the Bragg relation $(\lambda=d . \theta)$ applied to the position of the maxima is $80 \AA$. Though the intensity of the central scattering is decreased by a factor of ten when these peaks appear, there are also fluctuations in the position of the particles about their average : the order is consequently not perfect and the distance $d=80 \AA$ is over-estimated.

This inter-particle distance can be compared to the length $L$ of the rod equivalent to the polyion (using a diameter [8] of about 7-8 $\AA$ ) deduced from the radius 
of gyration $R_{\mathrm{g}}$. These results are summarized in table I and give an idea of the degree of stretching of the chain.

It is also possible to calculate a characteristic range for the electrostatic interaction, i.e. the radius $\chi^{-1}$ of the ionic atmosphere around each polyion [9]; the corresponding values (Table I) indicate $2 \chi^{-1} \simeq d$, confirming the previous models. Figure 2 shows as well a progressive decrease of the peak intensity when $\alpha_{s}$ changes from 0.6 to 1 . This phenomenon cannot be explained by the slight variation of the apparent coherent scattering length, expressing the solute-solvent contrast, when alkali is added to the solution, and has not yet been accounted for.

These preliminary experiments show the existence of an ordering between stretched polyelectrolytes in dilute solutions. The influence of the concentration can now be studied.

The experiments have been made on the EL 3 reactor of the Commissariat à l'Energie Atomique (Laboratoire Léon Brillouin, C.E.N. Saclay). We should like to thank Dr. R. Ober for his interest in this work and Professor C. Wolff for fruitful comments and discussions. The P.M.A. sample has been provided by Dr. R. Zana.

\section{References}

[1] TANFORD, C., Physical chemistry of Macromolecules (Wiley, New York) 1961.

[2] Moan, M., Wolff, C., C. R. Hebd. Séan. Acad. Sci. 274C (1972) 1492.

[3] Cotton, J. P., Decker, D., Benoit, H., Farnoux, B., Higgins, J., Jannink, G., Ober, R., Picot, C., Des CloiZEAUX, J., Macromolecules 7 (1974) 863.

[4] Allemand, R., Bourdel, J., Roudaux, J., Convert, P., Ibel, K., Jacobe, J., Cotton, J. P., Farnoux, B., Nucl. Instrum. Methods 126 (1975) 29.
[5] Moan M., WolfF, C., Ober, R., Polymer 16 (1975) 776.

[6] Cotton, J. P., Decker, D., Farnoux, B., Jannink, G., OBer, R., PICot, C., Phys. Rev. Lett. 32 (1974) 1170.

[7] GUINIER, A., Théorie et Technique de la Radiocristallographie (Dunod) 1974.

[8] Kurucsev, T., Rev. Pure, Appl. Chem. 14 (1964) 147.

[9] Oosawa, F., Polyelectrolytes (Marcel Dekker, Inc., N. Y.) 1971 , p. 34

[10] Cotton, J. P., Benort, H., J. Physique 36 (1975) 905. 